\title{
What critical thinking skills and dispositions do new graduates need for professional life? Views from Portuguese employers in different fields
}

Gonçalo Cruz , Rita Payan-Carreira , Caroline Dominguez , Helena Silva \& Felicidade Morais

To cite this article: Gonçalo Cruz , Rita Payan-Carreira, Caroline Dominguez, Helena Silva \& Felicidade Morais (2020): What critical thinking skills and dispositions do new graduates need for professional life? Views from Portuguese employers in different fields, Higher Education Research \& Development, DOI: 10.1080/07294360.2020.1785401

To link to this article: https://doi.org/10.1080/07294360.2020.1785401

Published online: 04 Jul 2020.

Submit your article to this journal

山 Article views: 18

Q View related articles $\sqsubset$

View Crossmark data $₫$ 


\title{
What critical thinking skills and dispositions do new graduates need for professional life? Views from Portuguese employers in different fields
}

\author{
Gonçalo Cruz (D) ${ }^{\mathrm{a}} \mathrm{d}_{*}$, Rita Payan-Carreira (1) ${ }^{\mathrm{b} *}$, Caroline Dominguez (D) ${ }^{\mathrm{a}, \mathrm{d} *}$, \\ Helena Silva (1D ${ }^{c, e}$ and Felicidade Morais (D) ${ }^{c, f}$
}

${ }^{a}$ School of Science and Technology, University of Trás-os-Montes and Alto Douro, Vila Real, Portugal;

bepartment Medicina Veterinária, Pólo da Mitra, Universidade de Évora, Évora, Portugal; 'School of Human and Social Sciences, University of Trás-os-Montes and Alto Douro, Vila Real, Portugal; ${ }^{d}$ Research Centre on

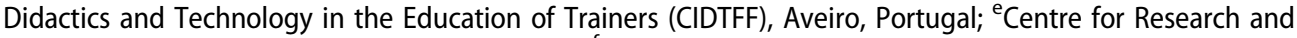
Intervention in Education (CIIE), Porto, Portugal; ${ }^{\mathrm{f} C}$ Centre for Studies of General and Applied Linguistics (CELGA-ILTEC), Coimbra, Portugal

\begin{abstract}
Even though Critical Thinking (CT) is an important goal for higher education institutions and labour market professionals, studies dealing with employers' perceptions on CT meaning and envisioning in the workplace are scarce. Intended to tackle this gap, the current study provides an overview of the need for and practical application of CT in the workplace from the employers' views. Adopting a qualitative research methodology, five focus group interviews were carried out, enrolling 28 representatives of different Portuguese Non-Governmental Organizations (NGO), public and private companies, in four different professional fields: Biomedicine, STEM (Sciences, Technology, Engineering and Mathematics), Social Sciences, and Humanities. Using Facione's framework for data analysis, results suggest that CT is broadly recognized by employers as a set of interdependent skills and dispositions that are needed in new graduates, presenting slight differences in their practical application across professional fields. This paper also discusses and outlines implications to support universities in the promotion of students' CT skills and dispositions.
\end{abstract}

\section{ARTICLE HISTORY}

Received 9 September 2018

Accepted 13 May 2020

\section{KEYWORDS}

Higher education; critical thinking; new graduates; labour market; employers

\section{Introduction}

The global challenges of the twenty-first century reinforce the need for Critical Thinking (CT) in a well-functioning society. Worldwide, employers frequently look for CT in new graduates (World Economic Forum [WEF], 2016). Nevertheless, serious concerns remain regarding an existing mismatch between students' CT and the labour market needs, suggesting that new graduates are not sufficiently prepared to think critically once in the workplace (Lane \& Oswald, 2016; Organisation for Economic Co-operation and Development [OECD], 2017). 
The need for additional University-Business Cooperation (UBC) initiatives emerges. Studies analysing the understanding and practical application of CT in different professional fields are scarce. Most of them lack methodological robustness, being limited to small sample sizes and number of disciplines, and/or narrowed to a skills-focused view of CT, neglecting its attitudinal dimensions (e.g., Jones, 2009; Moore, 2011; Sin, Jones, \& Wang, 2015).

Additionally, an ongoing tension exists regarding the nature of CT, namely whether it should be mainly understood as a generic or as a domain-specific skill (Davies, 2013; Moore, 2011). The academic point of view has been debated for decades, but for better clarity, it should be harmonized with the employers' perspectives. This exercise may lead to different implications, supporting universities in the widespread adoption of CT educational practices - for example, when deciding on the better approach to incorporate CT across the curriculum (Ennis, 2018).

This paper presents a qualitative exploratory research study aimed at examining CT understanding and application in the workplace based on the perceptions of Portuguese employers. It sought to answer the following research question: What CT skills and dispositions are valued in the Portuguese labour market? By identifying and characterizing the core CT skills and dispositions demanded in the workplace, this study discusses implications and draws pathways for universities to adopt CT educational practices aligned with labour market needs.

\section{Background}

Critical Thinking (CT) is a broad term with multiple interpretations, which have been debated over the years from different perspectives (Davies \& Barnett, 2015). Although many valid definitions and frameworks have been proposed (Ennis, 2016), this study adopted the one developed by a Delphi panel of 46 experts within different academic and professional fields (Facione, 1990, p. 3):

We understand critical thinking to be purposeful, self-regulatory judgment which results in interpretation, analysis, evaluation, and inference, as well as explanation of the evidential conceptual, methodological, criteriological, or contextual considerations upon which that judgment is based (...) The ideal critical thinker is habitually inquisitive, well-informed, trustful of reason, open-minded, flexible, fair-minded in evaluation, honest in facing personal biases, prudent in making judgments, willing to reconsider, clear about issues, orderly in complex matters, diligent in seeking relevant information, reasonable in the selection of criteria, focused in inquiry, and persistent in seeking results which are as precise as the subject and the circumstances of inquiry permit.

The Facione framework was adopted as the theoretical framework for this study for the following reasons: (1) it is a commonly used framework in the field; (2) it presumes and recognizes not only the cognitive, but also the attitudinal dimension of CT; and (3) it provides a detailed and operational definition of the core skills and dispositions that characterizes the 'ideal' critical thinker. Accordingly, CT is constituted by six main cognitive strands (i.e., skills) - 'interpretation', 'analysis', 'evaluation', 'inference', 'explanation' and 'self-regulation' (Facione, 1990, pp. 16-22) - and also by seven main attitudinal strands (i.e., dispositions) - 'truth-seeking', 'open-mindedness', 'analyticity', 'systematicity', 'self-confidence', 'inquisitiveness' and 'cognitive maturity' (Facione, Sánchez, 
Facione, \& Gainen, 1995, pp. 4-6). Albeit criticized by some as a reductionist approach (Davies \& Barnett, 2015), a framework is not static and may change in time and place, and should not preclude the identification of new CT strands if needed.

The scarce empirical research aiming to characterize how CT is needed, understood and applied in the labour market usually fails to consider the perspective of the employers or the workplace characteristics (Grosemans, Coertjens, \& Kyndt, 2017). Attempts to address these gaps exist, but the conclusions drawn from the studies are not always clear. Different reasons might explain this:

(1) the mismatch between the discourse used by researchers and employers is a barrier to data collection and analysis (Sin et al., 2015);

(2) the limited University-Business Cooperation (UBC) projects in curricula design, which focus mainly on research and development in terms of technology and knowledge transfer procedures (Galán-Muros \& Plewa, 2016);

(3) the research studies carried out are usually limited to small sample sizes and number of disciplines, or even restricted to a skills-focused view of CT that ignores the dispositional side of thinking (e.g., Grace \& Orrock, 2015; Jones, 2009; Moore, 2011).

At an earlier stage of the CT educational movement, the premise that CT has a similar understanding and application across disciplines led to the provision of generalist CT courses in higher education (Davies \& Barnett, 2015). This perspective is still supported by some authors (e.g., Davies, 2013), relying on the consideration that CT is generic in nature and teachable independently of the disciplines - for example, by delivering classes on informal logic. Conversely, others emphasize that the conceptualization of CT is influenced and shaped by the epistemological nature of the discipline in which CT is taught (Jones, 2009; Moore, 2011). As Jones (2009, p. 91) points out:

Critical thinking for a historian is about examining the evidence, about understanding context, acknowledging ambiguity, having an awareness of the ideological dimensions of a situation, and putting all these elements together to construct an argument. For a physicist it is an examination of the logic, accuracy and predictive powers of a model or solution, as well as an awareness of the areas of uncertainty in physics (...) In medicine, critical thinking requires, most importantly, good clinical reasoning. It also requires understanding of evidence-based medicine and an awareness of ethical issues.

The latter perspective seems to be starting to prevail among educators, leading to the adoption of CT subject-matter approaches in most of the universities nowadays (Abrami et al., 2015; Tiruneh, Verburgh, \& Elen, 2014). This is an important debate that must be held not only inside academia but also including and attending to employers' views, as it can result in different implications for the incorporation of CT across curricula.

\section{Method}

Drawing on a qualitative research approach (Creswell, 2014), an exploratory study was designed to explore and understand the meaning employers ascribe to CT and to the need for CT at the workplace. Specifically, it meant to delve into participants' perceptions concerning what CT skills and dispositions they valued in their professional fields. Thus, 
the current study aims neither to offer generalized results, nor to test existing hypotheses, but to provide a holistic, detailed picture of participants' views in a natural setting.

The focus group technique was adopted because of its characteristics (Krueger \& Casey, 2000). That is, a semi-structured discussion among a small, selected group of people, run by a facilitator, allowing researchers to generate qualitative data on a precise topic of interest, using a set of open-ended questions. It encourages people's thought and the development of new ideas, and values personal stories, beliefs and experiences in specific situations, while giving researchers the opportunity to guide the flow and direction of questioning.

The research process was arranged in four general, conceptual steps (Patton, 2002): planning, composition, implementation, and data analysis. The first step (planning) involved the definition of the participants' selection criteria and the elaboration of different documents required to organize the focus groups. This study followed the ethical requirements of the European Federation of Associations of Psychologists (EFPA), that is, informed consent, voluntary participation and confidentiality. The focus group evolved around an open question: 'What CT skills and dispositions do you consider to be the most important today and in the near future?'. Additional questions were introduced separately through the discussion (Appendix 1).

The potential participants were selected from the portfolio of institutional partners in different fields, after an initial phone call interview to ascertain their availability to participate in the study and according to their professional experience. A convenience sample was constituted with a cohort of 28 participants (Table 1), with at least 3 years of management experience in internal recruitment processes within their organizations, representing Portuguese private companies $(n=19 ; 68 \%)$, public organizations $(n=6 ; 21 \%)$ and NonGovernmental Organizations (NGO; $n=3 ; 11 \%$ ) (step 2, composition). The focus groups were assigned into four categories, representing different professional fields, namely: Biomedicine, STEM (Science, Technology, Engineering and Mathematics), Social Sciences, and Humanities. The fields were adapted from international classifications (e.g., ISCED-F, 2013; United Nations Educational, Scientific and Cultural Organization [UNESCO], 2013), comprehending several economic activities (European Statistical Office [Eurostat], 2008).

Five focus groups, each one engaging representatives from the same professional field, were carried out between November 2016 and January 2017 (Table 1). The interviews were conducted by two researchers (moderator and assistant) in the native language. Their average duration was 98 minutes (step 3, implementation).

The different fields were unevenly represented: Biomedicine enrolled $36 \%$ of the participants in the study $(n=10)$, Social Sciences 32\% $(n=9)$, and Humanities $21 \%(n=6)$,

Table 1. Summary of the focus groups interviews performed in each professional field.

\begin{tabular}{lllcr}
\hline $\begin{array}{l}\text { Professional fields } \\
\text { (UNESCO, 2013) }\end{array}$ & \multicolumn{1}{c}{$\begin{array}{c}\text { Economic activities } \\
\text { (Eurostat, 2008) }\end{array}$} & Identifier (ID) & $\begin{array}{c}\text { Number of } \\
\text { focus groups }\end{array}$ & $\begin{array}{r}\text { Number of } \\
\text { participants }\end{array}$ \\
\hline Biomedicine & Health & HEA & 1 & 5 \\
& Agronomics and Animal Sciences & AAS & 1 & 5 \\
STEM & Informatics Engineering & ENG & 1 & 3 \\
Social sciences & Tourism & TOU & 1 & 9 \\
Humanities & Arts and Culture & & 1 & 6 \\
Total & & & 5 & 28 \\
\hline
\end{tabular}


while STEM registered $11 \%(n=3)$. Seventeen participants $(61 \%)$ were men and $11(39 \%)$ were women; the age of participants ranged from 26 to 65 years.

Data were audio recorded and transcribed verbatim (step 4, data analysis). Each record was coded accordingly to the following system: [sector]_[number-of-participant]_[professional-field]. The codification was applied as follows: for the sector, NGO (Non-Governmental Organization), PB (Public sector) and PR (Private sector); for the participant, a number from 1 to $n$; the focus group identifier (ID) was extracted from the field name (e.g., HEA - Health).

Even though thematic analysis is conventionally used for data-rich focus groups, content analysis better suits when a set of pre-defined codes already exists, allowing the possibility of data quantification by measuring the frequency of different codes, which cautiously may stand as a proxy for significance (Vaismoradi, Turunen, \& Bondas, 2013). Thus, data analysis was conducted using a direct approach to content analysis (Hsieh \& Shannon, 2005). Considered as a deductive research approach, it uses theory-driven codes to extend conceptually a theoretical framework into an existing phenomenon or context, based on the following procedures (Hsieh \& Shannon, 2005, p. 1281): (1) formulation of predetermined coding schemes by identifying key concepts from theory as initial coding categories; (2) reading of transcripts and highlighting all texts appearing to represent the predetermined categories; (3) coding of highlighted text using the predetermined categories; and (4) attribution of a new code to any text that could not be categorized with the predetermined scheme (i.e., data-driven codes).

Data were initially coded and analysed independently by two pairs of analysts. The Facione framework was exclusively applied for data analysis and did not affect the personal perceptions shared by participants. Its core strands, namely the six CT skills (Facione, 1990, pp. 16-22) and the seven CT dispositions (Facione et al., 1995, pp. 46), were used as a priori codes. Other relevant codes emerging from data not fitting into the Facione framework were assigned to the 'out of the framework' category and also included in the data analysis.

The analysis was performed attending simultaneously to the frequency of a given code and to its rich description (Morgan, 1997). That is, the quotes of all participants were identified and counted whenever a participant positively referred to a given code followed by a clear description (i.e., emphasizing the importance of a specific CT skill or disposition with justification and/or an illustrative example). To avoid non-meaningful or decontextualized analysis, only participants' quotes within two different type of occurrences were counted: either when participants referred to the code in a new narrative (i.e., valuing a CT skill or disposition for the first time in a particular context) or when they agreed with other participants' statements referring to the code (i.e., agreeing on the importance of the mentioned CT skill or disposition in the given context). Afterwards, all the codes were reviewed by both pairs of analysts against the entire dataset iteratively, refining it in a process of resolving disagreement (Creswell, 2014).

\section{Results}

Data from focus groups interviews are presented in an attempt to answer the research question 'What CT skills and dispositions are valued in the Portuguese labour market?'. Data are firstly presented to show the overall perceptions of Portuguese employers from 
all the professional fields represented in the study. Secondly, data are presented to screen potential existing differences across the fields, reflecting the specific nature of each profession.

\section{Critical thinking in the workplace}

In general, professionals from different focus groups associated CT skills with CT dispositions in an interdependent way. CT dispositions were mentioned more often than CT skills (69\% vs. 31\%, respectively), also within specific fields: Biomedicine (66\% vs. $34 \%)$; STEM (61\% vs. $39 \%$ ); Social Sciences (77\% vs. $23 \%$ ); and Humanities (74\% vs. $26 \%)$. This reinforces the assumption that to think or act critically is mostly a matter of attitude. It was a consensual idea, as confirmed through several statements like the following:

More than training individuals who have a static knowledge, it is important to prepare them for more complex tasks, for uncertain contexts (...) All these are critical thinking skills, but I think it is not only to have the knowledge, nor to have the ability, it is to have this attitude which I think should be more developed. (PR_9_TOU)

All the core CT skills and dispositions identified in the Facione framework were mentioned by the participants. The highest emphasis was put on the 'self-regulation' skill (27\%; Figure 1) and the 'analyticity' disposition (28\%; Figure 2).

Other skills and dispositions not fitting into the Facione framework were also identified, namely: 'autonomy', 'communication', 'creativity', 'emotional maturity', 'empathy' and 'teamwork' (Figure 3). They can be assumed to be a core of complementary and interconnected strands, shaping the strong relationship between CT and the interpersonal dimension of a profession. Accordingly, CT appears to be applied beyond the individual bond, reflected in the sense of belonging to a team or system, in which

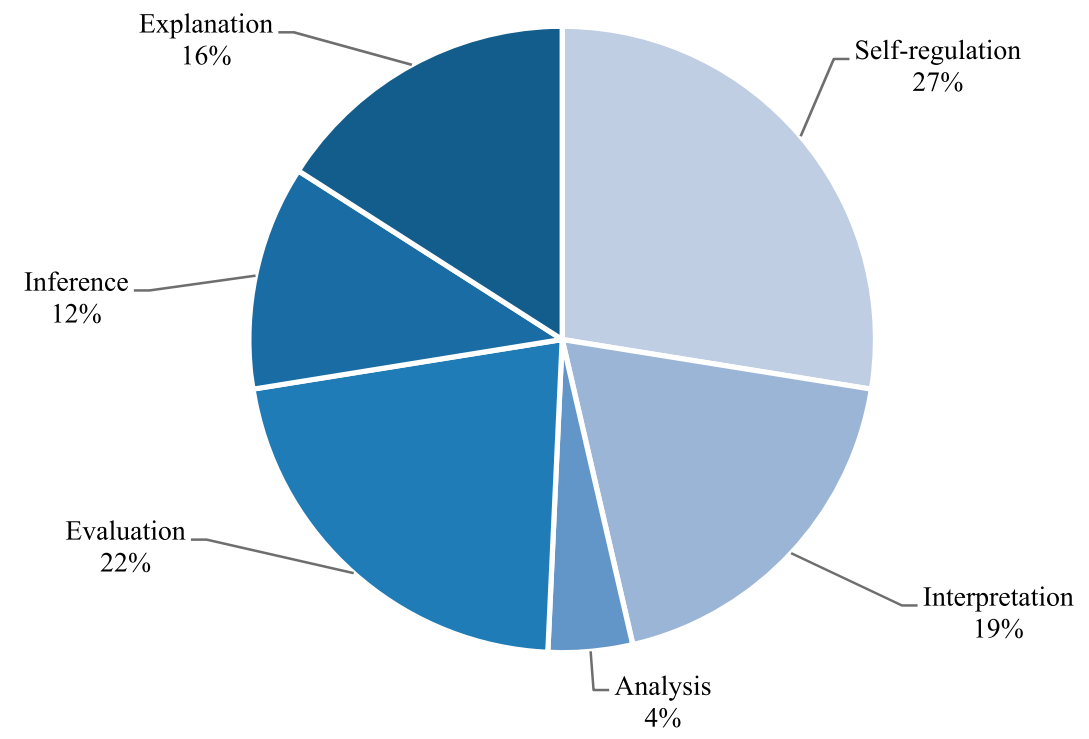

Figure 1. Critical thinking skills needed in the workplace. 


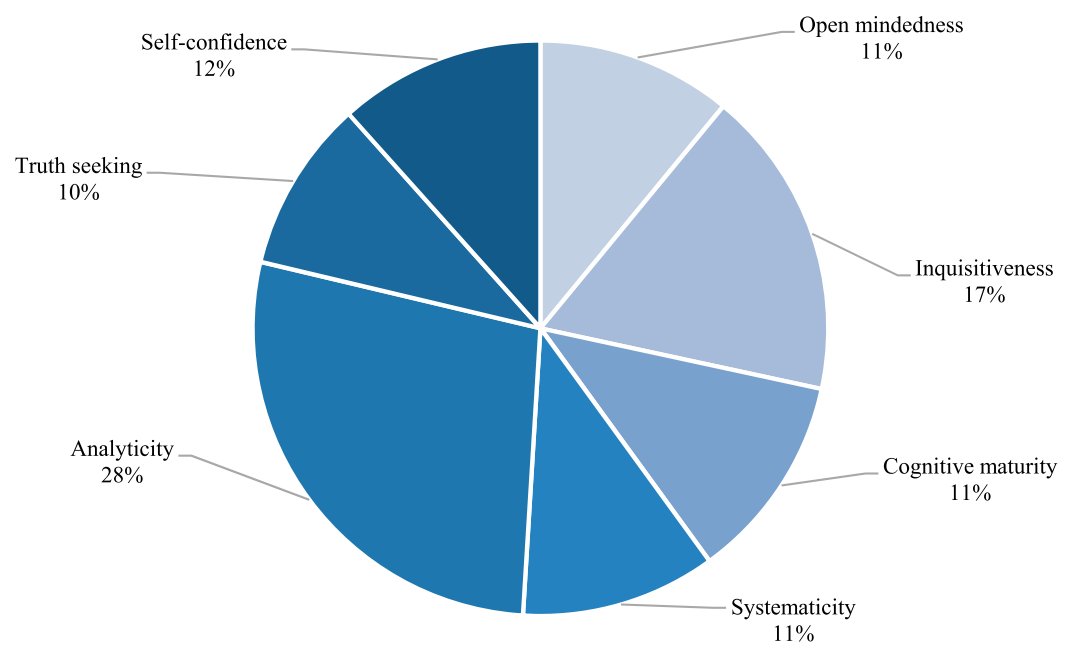

Figure 2. Critical thinking dispositions needed in the workplace.

communication, empathy and relation with the others (e.g., colleagues, patients, customers) play a crucial role in achieving desirable goals, better results or to make critical decisions.

Different frequencies were also found between fields, highlighting small nuances and similarities regarding the need for these skills and dispositions (Figures 4-6).

\section{Critical thinking in Biomedicine}

The 'evaluation' skill and the 'analyticity' disposition stood out among Biomedicine professionals (Figures 4 and 5), as essential to engage in clinical reasoning and judgement processes, especially in the complex and uncertain nature of healthcare situations (e.g.,

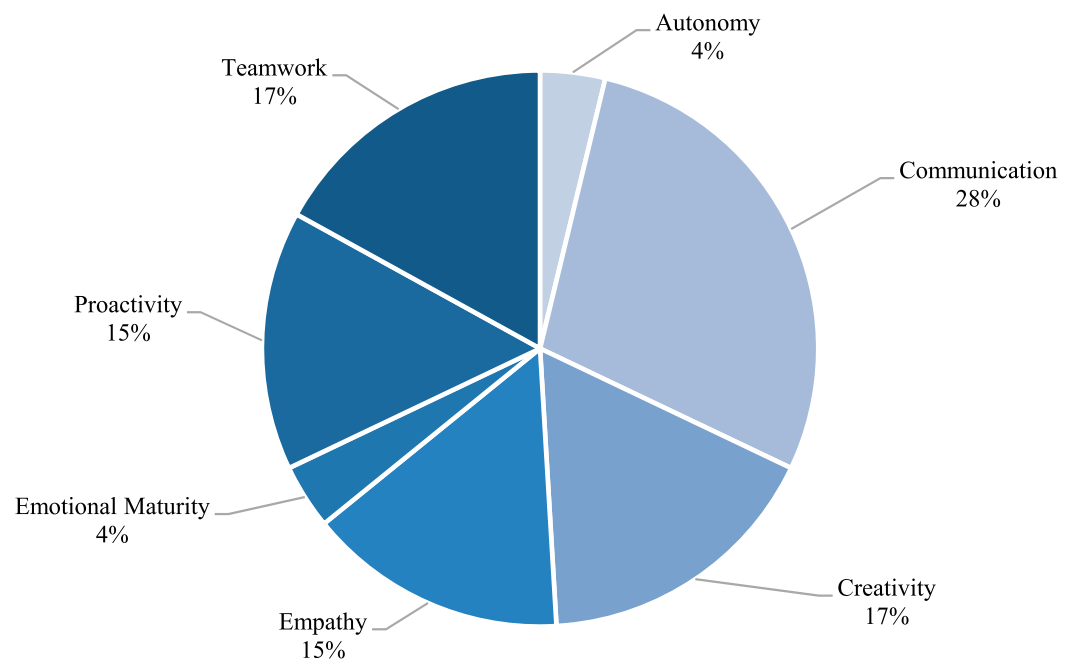

Figure 3. Other skills and dispositions needed in the workplace. 


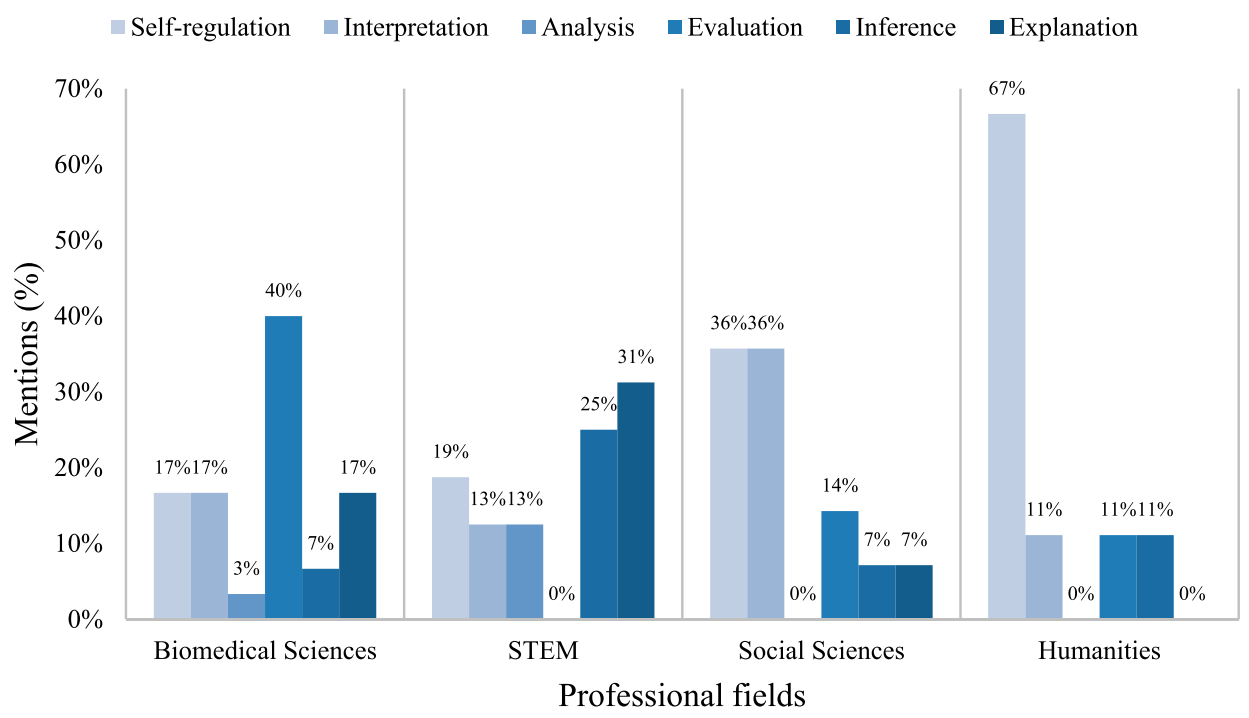

Figure 4. Critical thinking skills needed by professional field.

emergency). Both were related to pattern recognition, assessment of alternative scenarios, and prioritization of actions for decision-making:

I was talking to the patient, my colleague was seeing his [hyper]tension (...) and suddenly, I looked at him and said: "What's happening with you?". He said: "I'm sleepy". I noticed that he was with a reddish face and his lip started to get a little bit different (...) we saw that he was having a CVA [Cerebrovascular Accident] (...) this is a prompt decision, that is, to evaluate the situation, see in that moment that we couldn't do the medication there. No. It's necessary to call the emergency number. It was important to know in that moment that it was serious,

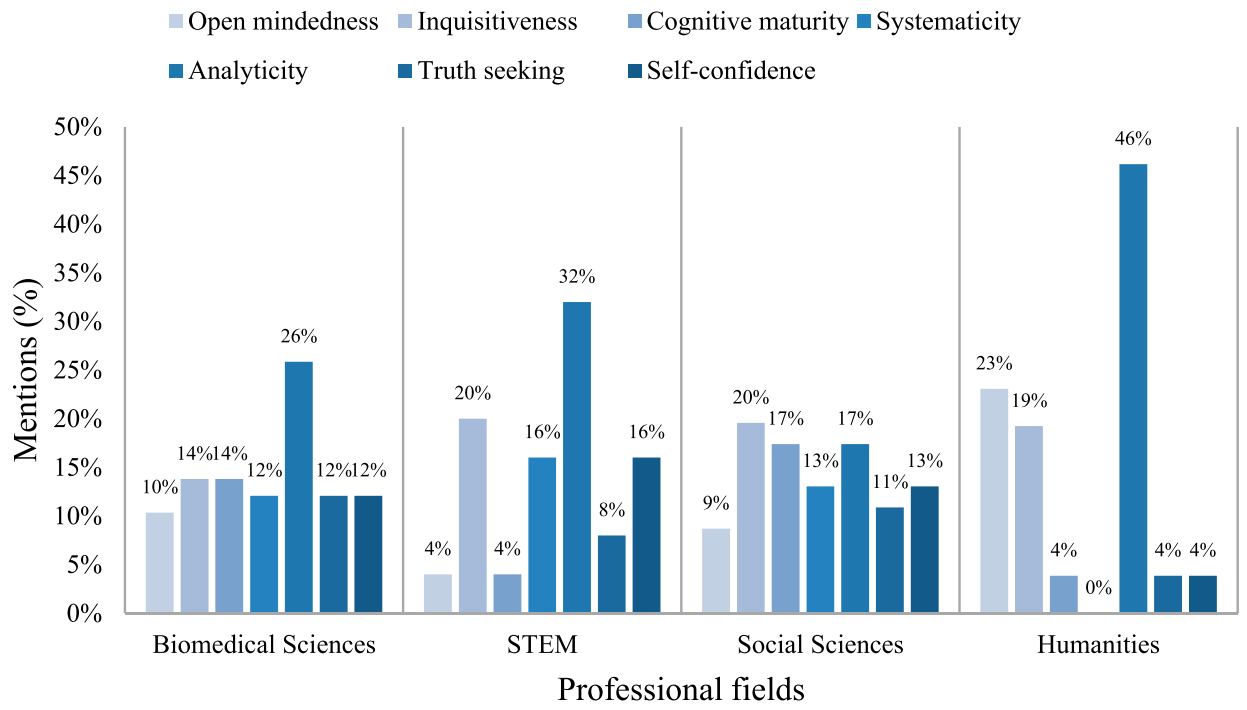

Figure 5. Critical thinking dispositions needed by professional field. 


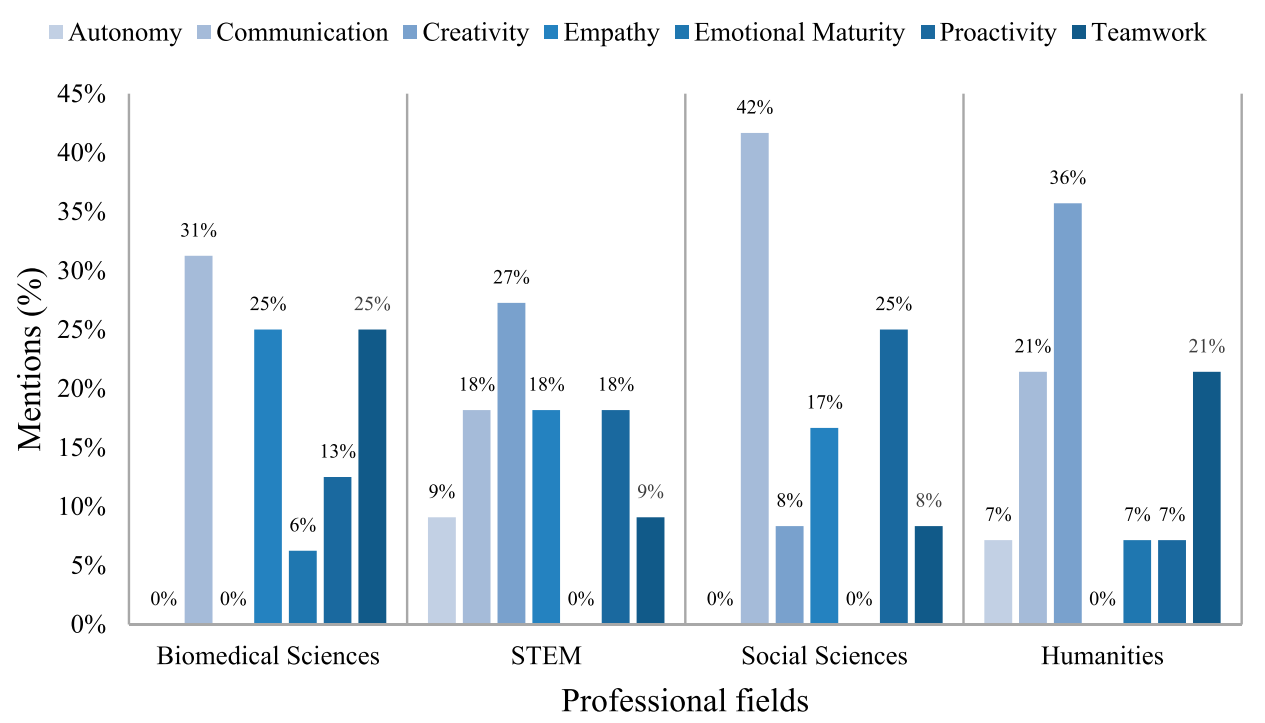

Figure 6. Other skills and dispositions needed by professional field.

that he [the patient] already had symptoms and he had initiated the CVA in front of us (...) So, it was an informed decision, based on criteria. (PB_2_HEA)

The 'interpretation' and 'explanation' skills were highlighted for diagnosis and prescription purposes. Every professional must not only know how to decode, understand and categorize data from different statements or examinations (e.g., patients' complaints, clinical history, symptoms), but also justify and explain the clinical follow-up procedures to the patient or family, making them co-responsible in the treatment. Both were linked to strong 'communication' skills and 'empathy', as also claimed by the interviewees (Figure 6).

The 'self-regulation' skill was stressed as essential for professional improvement. It represents an ongoing metacognitive process for physicians and nurses who are concerned to critically reflect and self-monitor their performance. It can be developed by post-practice evaluation through clinical auditing:

That is why [we do] this data collection; this analysis, to look for the reasons for success or not, must constantly grow within each one of us. It must be trained permanently. Most of the critical spirit that I develop regarding our procedures comes from auditing processes. (PB_1_HEA)

The 'cognitive maturity' disposition was associated with ethical reasoning, considering the moral values and principles within a medical setting (e.g., non-maleficence, human rights). It calls for intellectually honest and open-minded professionals, aware of their own bias, and conscious of their respect for human life. Here, some tension between the 'cognitive maturity' and the 'self-confidence' dispositions was identified, as illustrated:

I cannot scare a patient about a serious pathology. I have to quickly see, decide and transmit the orientations for those [colleagues] who need to act (...) When a physician faces a patient, he also faces himself. He has to develop the critical thinking in this sense: neither put himself in the situation of incapable, nor in the situation of fully capable. (PB_1_HEA) 
The 'inquisitiveness' and 'truth-seeking' dispositions were both expressed by the desire to learn and update professional knowledge, whether in specific situations (e.g., seeking for the best knowledge during initial medical screening) or in a broader and lifelong learning perspective (e.g., engaging with lifelong learning and professional development). The need for the 'systematicity' disposition was also pointed out, expecting new graduates with organizational abilities to comply with different medical protocols (e.g., to prioritize and manage different tasks in a limited timeframe as a medical appointment).

\section{Critical thinking in STEM}

Professionals from the information technology consulting branch drew particular attention to the need of the 'explanation' skill in new graduates (Figure 4). In this scope, they emphasized it as a persuasive way of thinking (e.g., thinking around how to positively influence the customers by presenting one's own reasoning in the form of cogent arguments):

The ability to define and convey objectives, guidelines, check the evolution trends, or also influence, persuade - how can a person influence and persuade their customers, isn't it? (PR_2_ENG)

This way of thinking relates to other key CT skills and dispositions such as 'inference', 'analyticity' and 'systematicity'. You can only achieve it if the provision of solutions in response to the clients' problems involves abstract thinking and questioning. However, what counts here is not only if professionals are capable of asking good questions or conjecture alternatives, but also if they are able to engage with problem-solving procedures (e.g., problem representation, decomposition) in a systematic way during the process:

We are basically producers of knowledge - aren't we? We look at a situation with different lenses that are independent, to characterize the roots of the problems. And then point out clues or recommendations to our clients. That requires to gather data, to ask informed questions, but if I cannot transfer them to a paper, to an idea, if we cannot arrange them in order to frame and systematize the problem (...) It's not about coming up with a right or a wrong result. It is more about the way they [candidates] build the solution, the thinking process (...). (PR_1_ENG)

The 'self-regulation' skill and the 'inquisitiveness' disposition were also claimed by participants. The first was expressed both as an individual reflection regarding one's own performance, and as a co-regulatory process (e.g., engaging colleagues in self-reflection). The second, alike in Biomedicine, was somehow related with professional scepticism and the 'truth-seeking' disposition, which require the commitment of new graduates to a constant update of their professional knowledge and development.

The 'self-confidence' disposition was linked by the participants to the courage to take a position or to apply a different solution without being afraid of the judgements of others. In some cases, it can assume a form of proactive but silent leadership, driving employees to act and take initiative without previous communication with supervisors or senior positions:

He [new graduate] was in a controversial situation, in which he had a person hierarchically above who said: "No, it should be done this way". But then he had his own belief that it should be done differently (...) he did not limit himself to program and develop the 
[software's] code that they [supervisors] asked for, but to think critically in order to defend his idea until the end, without excluding anyone - he [the new graduate] did not only what the supervisor wanted but he did it also the way he thought best (...). (PR_3_ENG)

\section{Critical thinking in social sciences}

Tourism employers identified 'interpretation' and 'self-regulation' at the top of core CT skills needed in new graduates (Figure 4). The first was represented by the ability to decode significance and to clarify meaning, and was also associated with the 'explanation' skill. It can apply in scenarios where professionals need to identify the profile of a specific group or client (e.g., during a cultural tour, doing the check-in at hotel reception):

[During the tourist visits] we can have people from different economic, social and cultural backgrounds in the group and we have to know how to transfer the information to them in the most appropriate way. (PR_5_TOU)

The second was expressed both in the form of self-monitoring and self-correction. Thus, professionals not only need to keep questioning their performance (e.g., looking for cognitive bias), but also refining and modifying it. That seems to bring an added value to the service provided to the client, as illustrated by one participant:

One would say that it is effortless to book a flight for a client; it does not request critical thinking but only some technical skills. What is more important is to do what people alone can't do, what the internet doesn't provide. And here comes the importance and added value of a travel agency (...) because if people are not thinking on what they are doing and don't have self-criticism on whether what they are doing is the best procedure or not, if it's correct and if there will be ways to do it better, we often can't distinguish ourselves from what everyone alone can do; that is, to book a flight. (PR_6_TOU)

Professionals also highlighted the need for the 'analyticity' disposition and the 'evaluation' skill. It deals with an ongoing reasoning attitude to anticipate problems and assess the context, which can arise in the form of a more situational (e.g., a pilot in the airplane when something goes wrong) or holistic assessment. The last tends to be a requirement of today's market, increasingly complex and dynamic. For instance, a participant emphasized the ability to assess the social, political and geographical factors (e.g., social and political conflicts, migration tendencies) that shape the global scenario:

[referring to the need for a constant analytical attitude] Due to the large number of players today the tourism market behaviour is completely different (...) For instance, due to all the social conflicts and instability in the zone of the Mediterranean (e.g., Greece, Turkey), our traditional partners in Algarve [a Portuguese region and a typical/common destination for vacation] now don't want to work with us [a particular touristic agency]. Why? Because of this shift on Algarve's increasingly demand, they have Russian and English investors who book the region for the whole year [the conflicts lead English agencies to prefer Algarve and rule the market] and offer competitive prices, while we usually booked only for 3 months period and we are no longer interesting. That drove the need to buy from an English player to resell it to Portuguese when we previously bought and sold it directly to the customer. (PR_7_TOU)

Other CT dispositions, such as 'inquisitiveness' and 'systematicity', deserved the attention of the participants. The first was expressed by the desire to learn and acquire professional experience (e.g., by travelling and knowing other cultures). The second was illustrated by 
the habit to solve problems or take decisions in a structured way, requiring the perseverance that new graduates seem to lack when acting too hastily:

They [new graduates] want constant challenges (...) they don't have patience to learn, they want to get in a company and quickly start to manage projects; they want constant challenges, they are not able to stop and analyse information, they access it and instantaneously forget it. (PR_3_TOU)

\section{Critical thinking in humanities}

Employers from Arts and Culture considered 'self-regulation' to be the most important CT skill (Figure 4). They related it with a particular kind of intellectual openness and humility, favourable to a constant analytical process of personal weaknesses and strengths, challenges and opportunities for improvement. A participant highlighted some interdependence between the 'self-regulation' CT skill and 'emotional maturity', which (naturally) seems to be present in a performative art as in theatre, where professionals act under the pressure of an emotionally engaged audience:

An actor lives in a constant self-criticism; he is never happy, even after the premiere. (...) We are always under stress and pressure, from the audience, the director. An actor does not sleep before the debut, does not eat (...) I would like to intersect critical thinking with this question of emotional intelligence. (...) a theatre actor, as mediator, works with a receiver who is equal to him, who cries and laughs. And above all, if the actor does not have this emotional intelligence, he will not be able also to have this thinking capacity and time for self-criticism. (NGO_5_ARTS)

Regarding CT dispositions, the need for 'open-mindedness' was identified due to the financial constraints that cultural organizations face nowadays in hiring people. Such reality was stated by different participants, as in the following example:

This comes from the weaknesses of the market and the smaller capacity to hire people. Of course, people have to be flexible; a sound technician has to help the light technicians, or the video technicians, or eventually engage with management tasks. (PB_3_ARTS)

The 'analyticity' disposition was also claimed in this field. It was referred to as an ongoing attitude to systematically engage with reasoning, allowing new graduates to be ready to act or intervene at any moment in abnormal or unexpected situations (e.g., during an unexpected error in a theatre scene). This kind of improvization can be easily related to 'creativity', which was also stressed by these participants (Figure 6). Both creativity and CT are interdependent forms of thinking for these professionals. As one participant illustrated, the creation of an artistic object is built upon a strong analytical process, even if expressed in a subjective way:

What defines an artist can be this ability to think about the reality, about what is ahead of him/her, ahead of all, and through this observation and thought, he modifies that reality transforming it in an artistic object. (PB_3_ARTS)

\section{Discussion}

To answer the question of 'What CT skills and dispositions are valued in the Portuguese labour market?' is neither simple nor linear. In fact, all the Facione CT skills and 
dispositions were mentioned by the participants. The key findings suggest that employers' perspectives comply with Facione's framework to the extent that CT is represented by a core of interdependent skills and dispositions that are unquestionably needed in new graduates. The first implication that emerges here is not new: universities must have a clear mission statement recognizing CT as an important goal, and explaining how it can be accomplished according to labour market needs. Failing to do so will keep driving the CT skills mismatch and/or shortage in the new graduate students at day 1 (Lane \& Oswald, 2016; OECD, 2017).

The emphasis on dispositions suggests that CT might not be fully developed on a shortterm basis. It is something to be consolidated by experience, lifelong learning, and continuous effort. Both CT skills and dispositions empower people to think and act critically. As Barnett (2012, p. 65) suggests:

(...) learning for an unknown future has to be a learning understood neither in terms of knowledge or skills but of human qualities and dispositions. Learning for an unknown future calls, in short, for an ontological turn.

This is a strong pedagogical challenge for teachers and implies that universities should invest in teacher training and support (e.g., by fostering professional learning communities around CT teaching practices or embedding CT within the institutional quality teaching frameworks). It requires universities to stop adopting CT teaching practices only at the course level, and to start aligning them at the teaching programme level (Cruz, Payan-Carreira, \& Dominguez, 2017).

Our findings also add some implications to the 'generalist vs. disciplinary' debate in the field. On one hand, and in line with the generalists (e.g., Davies, 2013), it was interesting to find that professionals across fields interpreted the Facione strands with a similar general understanding and need. For them, an ideal CT professional must present an informed habit of thinking and the desire to learn and improve both personally and professionally. However, not everyone can be the 'ideal critical thinker' claimed by Facione (1990, p. 3). Even though it seems meaningless to set a minimum of CT skills or dispositions to be developed, at the risk of atomizing CT, it is important to consider the core CT skills and dispositions identified by the majority of employers - self-regulation and analyticity, respectively. Those allow students to anticipate and be prepared for any situation, as well as to regulate and monitor their thinking and behaviour processes.

On the other hand, and in line with the specifists (Jones, 2009; Moore, 2011), slight nuances were encountered between the fields, suggesting that the Facione framework strands are also bonded to a disciplinary or professional context. Actually, in Biomedicine, CT includes the thinking over different aspects of healthcare and wellbeing, to support decision-making, to obtain a plausible conclusion regarding prevention, diagnosis or treatment of a specific patient. It considers various priorities, ethical concerns or medical protocols. In STEM, CT requires persuasive reasoning and systematic thinking about problems and different approaches to meet the best solutions or outcomes attending to a given need, goal or expectation of a specific customer. In Social Sciences, CT is seen as a desirable set of skills and dispositions for professional improvement. It brings an added value into the management and provision of quality services and products to clients during their leisure experiences (e.g., in the case of Tourism professionals, as studied here). In Humanities, CT is expressed by thinking about the reality, about what 
is around the actor and the backstage. Through this analytical process, reality is transformed into an artistic expression that is shared with an emotionally engaged audience.

Therefore, the current study showed that, despite the common understanding of CT skills and dispositions, employers place more emphasis on some of the Facione strands than others, with specific needs and understandings according to each professional context. The implications for the universities here include the need to consider both the generic and the discipline-specific nature of CT, as it is proposed elsewhere (Ennis, 2018). That is, rather than adopting the standalone CT subject-matter approach that prevails in most of the universities nowadays (Abrami et al., 2015; Tiruneh et al., 2014), the generic nature of CT should be considered. Thus, faculty members should develop explicit CT instructional courses separately from the subject-matter content and, at the same time, encourage students to think critically within subject-matter instruction.

Lastly, professionals transcended the Facione framework used for the data analysis (Facione, 1990), understanding CT in a broader perspective, calling for new related strands - for example, 'creativity', 'empathy', 'emotional maturity'. These are essential not only for professional and organizational efficiency, but also for personal improvement and common good. They also play a major role in directing professionals to the desired outcome and to attend to people's needs and expectations, considering different ethical and social concerns. However, employers mainly emphasized a pragmatic necessity of CT towards the success, efficiency or profit of their own business/organizations. Thereby, other CT strands as the ones entrenched in social justice and dialogical strategic questioning practice (Giroux, 2014) were not so easily captured in the participants' discourses - for example, the importance of a critic participation of health professionals in the construction of the national health policies, arguing against authorities and power structures. For educational researchers, this implies the need to study CT beyond the Facione framework and try to explore in depth other strands that have been proposed by recent research (Davies \& Barnett, 2015).

\section{Limitations and future directions}

Our aim was not to make generalized inferences concerning the employers' understanding of CT. We assume that participants' background influenced their own perceptions and beliefs towards it. The uneven representation of the sample needs to be considered and the number of participants in each field may have impacted the final results. Thus, other types of studies (e.g., survey research) are encouraged to identify and explain trends of larger groups of professionals regarding the need for CT at workplace. Additionally, proper distinctions between CT and other strands claimed by employers (e.g., communication, creativity, emotional maturity) were not clarified here and still need scrutiny.

\section{Conclusion}

The research presented here contributes by deepening understanding about the application of CT in the Portuguese workplace through analysing employers' perceptions on this topic. It attempts to fill the gap from a scarcity of studies found in the field. Furthermore, it contributes to better draw pathways for the alignment of higher education curricula with labour market needs. 
The emphasis on CT dispositions demanded by the workplace highlights the importance of universities in redesigning their curricula and adapting pedagogies. That is, universities need to ensure not only that teachers are capable of enhancing students' CT dispositions, but also that these pedagogies are aligned at the teaching programme level, since CT development encompasses continuous effort and long-term practice.

Similarities and differences in the understanding and application between professional fields implies that universities have an integrated strategy to support CT teaching practices. If the provision of generic courses on CT can cover the common strands needed within the different professional fields (e.g., self-regulation, analyticity), it seems that a gradual CT infusion within subject-matter courses, attending to the epistemological nature of each specific field, would be an added value.

Finally, participants' CT understanding was mainly characterized by the Facione strands and the desire to train future professionals to be adaptable and autonomous, bringing efficiency, profit and success to the organization. However, other strands emerged from the data and should not be undervalued by higher education institutions (e.g., creativity, empathy, emotional maturity, proactivity, teamwork). This suggests the need for a reconsideration of universities' mission in both the development of successful business entrepreneurs and participatory citizens that can transform the workplace.

\section{Acknowledgements}

The European Commission support for the production of this publication does not constitute an endorsement of the contents which reflects the views only of the authors, and the Commission cannot be held responsible for any use which may be made of the information contained therein.

\section{Disclosure statement}

No potential conflict of interest was reported by the author(s).

\section{Funding}

This work was supported by the European Commission/Education, Audiovisual and Culture Executive Agency (EACEA) [grant number 2016-1-PT01-KA203-022808].

\section{ORCID}

Gonçalo Cruz (iD http://orcid.org/0000-0003-4738-3910

Rita Payan-Carreira (D) http://orcid.org/0000-0001-5225-4510

Caroline Dominguez (D) http://orcid.org/0000-0002-8486-4142

Helena Silva (1) http://orcid.org/0000-0003-2855-9634

Felicidade Morais (iD http://orcid.org/0000-0001-5772-8930

\section{References}

Abrami, P., Bernard, R., Borokhovski, E., Waddington, D., Wade, A., \& Persson, T. (2015). Strategies for teaching students to think critically: A meta-analysis. Review of Educational Research, 85(2), 275-314. doi:10.3102/0034654314551063 
Barnett, R. (2012). Learning for an unknown future. Higher Education Research \& Development, 31 (1), 65-77. doi:10.1080/07294360.2012.642841

Creswell, J. (2014). Research design: Qualitative, quantitative, and mixed methods approaches (4th ed.). Thousand Oaks, CA: Sage.

Cruz, G., Payan-Carreira, R., \& Dominguez, C. (2017). Critical thinking education in the Portuguese higher education institutions: A systematic review of educational practices. Revista Lusófona de Educação, 38, 43-61. doi:10.24140/issn.1645-7250.rle38.03

Davies, M. (2013). Critical thinking and the disciplines reconsidered. Higher Education Research \& Development, 32(4), 529-544. doi:10.1080/07294360.2012.697878

Davies, M., \& Barnett, R. (2015). Introduction. In M. Davies \& R. Barnett (Eds.), The Palgrave handbook of critical thinking in higher education (pp. 1-25). New York: Palgrave Macmillan.

Ennis, R. (2016). Definition: A three-dimensional analysis with bearing on key concepts. In L. Benacquista \& P. Bondy (Eds.), Argumentation, objectivity, and bias: Proceedings of the 11th international conference of the Ontario society for the study of argumentation (OSSA) May, 18-21 (pp. 1-19). Windsor, ON: OSSA.

Ennis, R. H. (2018). Critical thinking across the curriculum: A vision. Topoi, 37(1), 165-184. doi:10. 1007/s11245-016-9401-4

European Statistical Office. (2008). NACE Rev. 2: Statistical classification of economic activities in the European community. Luxembourg: Office for Official Publications of the European Communities. https://bit.ly/1EKGS03

Facione, P. A. (1990). Critical thinking: A statement of expert consensus for purposes of educational assessment \& instruction: The Delphi report. Millbrae, CA: California Academic Press. https://bit. ly/2IZi8FY

Facione, P. A., Sánchez, C. A., Facione, N. C., \& Gainen, J. (1995). The disposition toward critical thinking. Journal of General Education, 44(1), 1-25.

Galán-Muros, V., \& Plewa, C. (2016). What drives and inhibits university-business cooperation in Europe? A comprehensive assessment. R\&D Management, 46(2), 369-382. doi:10.1111/radm. 12180

Giroux, H. (2014). When schools become dead zones of the imagination: A critical pedagogy manifesto. Policy Futures in Education, 12(4), 491-499. doi:10.2304/pfie.2014.12.4.491

Grace, S., \& Orrock, P. J. (2015). Criticality in osteopathic medicine: Exploring the relationship between critical thinking and clinical reasoning. In M. Davies \& R. Barnett (Eds.), The Palgrave handbook of critical thinking in higher education (pp. 475-490). New York: Palgrave Macmillan.

Grosemans, I., Coertjens, L., \& Kyndt, E. (2017). Exploring learning and fit in the transition from higher education to the labour market: A systematic review. Educational Research Review, 21, 67-84. doi:10.1016/j.edurev.2017.03.001

Hsieh, H.-F., \& Shannon, S. E. (2005). Three approaches to qualitative content analysis. Qualitative Health Research, 15(9), 1277-1288. doi:10.1177/1049732305276687

Jones, A. (2009). Redisciplining generic attributes: The disciplinary context in focus. Studies in Higher Education, 34(1), 85-100. doi:10.1080/03075070802602018

Krueger, R., \& Casey, M. (2000). Focus groups: A practical guide for applied research. Newbury Park, CA: Sage.

Lane, D., \& Oswald, F. L. (2016). Do 45\% of college students lack critical thinking skills? Revisiting a central conclusion of academically adrift. Educational Measurement: Issues and Practice, 35(3), 23-25. doi:10.1111/emip.12120

Moore, T. J. (2011). Critical thinking and disciplinary thinking: A continuing debate. Higher Education Research \& Development, 30(3), 261-274. doi:10.1080/07294360.2010.501328

Morgan, D. L. (1997). Focus groups as qualitative research (2nd ed.). Thousand Oaks, CA: Sage.

Organisation for Economic Co-operation and Development (2017). Getting skills right: Skills for Jobs Indicators. Paris: OECD. doi:10.1787/25206125

Patton, M. Q. (2002). Qualitative evaluation and research Methods. Thousand Oaks, CA: Sage. 
Sin, S., Jones, A., \& Wang, Z. (2015). Critical thinking in professional accounting practice: Conceptions of employers and practitioners. In M. Davies \& R. Barnett (Eds.), The Palgrave handbook of critical thinking in higher education (pp. 431-456). New York: Palgrave Macmillan.

Tiruneh, D., Verburgh, A., \& Elen, J. (2014). Effectiveness of critical thinking instruction in higher education: A systematic review of intervention studies. Higher Education Studies, 4(1), 1-15. doi:10.5539/hes.v4n1p1

United Nations Educational, Scientific and Cultural Organization (2013). ISCED fields of education and training 2013 (ISCED-F 2013). https://bit.ly/2p3O1oE

Vaismoradi, M., Turunen, H., \& Bondas, T. (2013). Content analysis and thematic analysis: Implications for conducting a qualitative descriptive study. Nursing \& Health Sciences, 15(3), 398-405. doi:10.1111/nhs.12048

World Economic Forum. (2016). The future of jobs: Employment, skills and workforce strategy for the fourth industrial revolution. Cologny: World Economic Forum. https://reports.weforum.org/ future-of-jobs-2016/

\section{Appendix 1. Questions used for data collection}

(1) What CT skills/dispositions are you looking for while employing university' graduates in your organization?

(2) What CT skills/dispositions do your employees/colleagues master?

(3) What CT skills/dispositions are of the most importance today?

(4) What CT skills/dispositions have to be improved/acquired today?

(5) What CT skills/dispositions will be needed in the near future in your organization? 